\title{
Research
}

\section{Managing Rangeland as a Complex System: How Government Interventions Decouple Social Systems from Ecological Systems}

Wenjun $\mathrm{Li}^{1}{ }^{1}$ and Yanbo $\mathrm{Li}^{1}$

\begin{abstract}
The complexity of natural resource management is increasingly recognized and requires adaptive governance at multiple levels. It is particularly significant to explore the impacts of government interventions on the management practices of local communities and on target social-ecological systems. The Inner Mongolian rangeland was traditionally managed by indigenous people using their own institutions that were adapted to the highly variable local climate and were able to maintain the resilience of the social-ecological system for more than 1000 years. However, external interventions have significantly affected the rangeland social-ecological system in recent decades. In this paper, using livestock breed improvement as an example, we track government interventions from the traditional era through the collective period to the present market economy period based on a review of historical documents and case studies. Using the concept of social-ecological system resilience, we diagnose the impacts of interventions on livestock breed management in the rangeland social-ecological system, and discuss how these interventions occur. We found that government interventions in livestock breeding have gradually decoupled the pastoral society from its supporting ecological system. During this process, external powers have increasingly displaced the local community in defining the nature of rangeland management. Power asymmetry and discourse have contributed to this displacement.
\end{abstract}

Key Words: decoupling; Inner Mongolia; rangeland management; resilience; social-ecological system

\section{INTRODUCTION}

The complexity of natural resource management is increasingly recognized as a result of our improved understanding of the complexity of ecological dynamics (Scoones 1999, Berkes et al. 2003) and social processes (Agrawal 2003, Johnson 2004, Sick 2008), as well as our improved understanding of the tight interaction and feedbacks between human social systems and the ecological systems that sustain them (Scoones 1999, Berkes et al. 2003, Liu et al. 2007, Robinson 2009). Realizing such complexity has challenged natural resource management worldwide; scholars have thus introduced the concept of the social-ecological system (SES) into the field of natural resource management (Anderies et al. 2004, Folke et al. 2005, Ostrom 2007, 2009). On the one hand, the SES concept emphasizes the coupling between natural and social systems. On the other hand, it underlines the complexity of such systems.

Understanding the concept of resilience is critical in managing such complex systems. Resilience represents the capacity of a system to endure shocks without significant damage to its functions, structure, feedbacks, and identity (Walker et al. 2006). Resilience theory emphasizes the maintenance of a system's function as a whole, such as that of an SES, its adaptation to disturbances and uncertainties, and the importance of adaptive governance in SES management (Scoones 1999, Folke et al. 2005, Lebel et al. 2006, Olsson et al. 2006).

For many years, natural resource management has been dominated by a command-and-control philosophy that Holling and Meffe (1996) described as the pathology of natural resource management, which has attempted to simplify the complexity of such systems by focusing on a few variables, but that inevitably results in undesirable outcomes and surprises, and generally compromises the SES's resilience. If we want to avoid the problems created by command-andcontrol management by adopting the perspective of resilience, we must obviously understand the role of the government, as a necessary agent in any resource management system, and its interactions with other stakeholders, particularly the communities that will be affected by the government's actions, as well as the impacts of such interactions on the system to be managed. Many studies (Li 2002, Ratner 2006, Benjamin 2008, Clement and Amezaga 2009) have explored the impacts of government interference on resource management by local communities, but have mainly focused on interference that directly targets local resource management institutions through interventions such as privatization, enclosures and exclusions, and decentralization. However, there has been little research on interventions in the technology of resource utilization and management (Rammel et al. 2007). Technology is generally considered to be value-neutral, and therefore little attention has been paid to the impacts of technological interventions on resource management institutions. This represents a significant gap in our understanding, because technological interventions have been widely employed by governments and by many international development agencies in natural resource management, especially in ecologically and economically marginal areas.

In this paper, we used the rangeland SES of China's Inner Mongolia Autonomous Region as a case study of the impacts 
of technological interventions by a national government. Specifically, we considered livestock breed improvement to explore the impacts of an external government's interventions on the rangeland and on rangeland management by the local community in arid and semiarid areas of China, with a focus on the social and economic contexts at and above the community level. The rangeland SES comprises a bundle of "commons" that include the region's vegetation and subsurface water, which was and still is utilized in common, as well as the shared indigenous livestock genetic material, shared cultural practices of the indigenous groups, and sometimes shared economic activity, such as herder cooperatives. These subsystems are tightly connected and often mutually reinforced in supporting the resilience of the system as well as supplying ecosystem services through the interactions and feedbacks among them. In such a system, any interference with one component will affect other components and potentially even the entire system. The livestock genetic resource, i.e., the breed, is an essential feature that determines an animal's ability to adapt to the environment of an ecological system, but in terms of the social system, it also determines the production conditions requirement and the productivity of the animals. Thus, livestock breeds represent an important link between the social and natural spheres of Inner Mongolia's pastoral society.

Traditionally, the main approach used in livestock breed improvement was based on the selection of excellent individuals from native herds, followed by mating the best with the best. More modern techniques have introduced exotic breeds to replace the native animals or have used them to crossbreed with native animals. In the present study, "livestock breed improvement" refers to the latter approach. Livestock breed improvement has been widely employed to improve livestock performance in the world's arid and semiarid areas, especially since the 1920s in Africa (Scoones 1990, Ahuya et al. 2005), where livestock breed improvement was used as a development strategy. However, because of the region's harsh environment, incompatibility between the breeding objectives and the management approaches used by local subsistence production systems, and institutional changes, there have been few success stories (Ayalewa et al. 2003, Ahuya et al. 2005, Kosgey et al. 2006). Many scholars have explored the process and feasibility of livestock breed improvement in African subsistence pastoralism (Ayalewa et al. 2003, Kosgey et al. 2006, Moll et al. 2007, Kosgey et al. 2008), as well as its impacts on biodiversity and food security around the world (Travis 1992, Thorp 2001, Tisdell 2003, Wilson and Tisdell 2005). These researchers have warned that there are potentially serious consequences of such interventions on local people's sustainable livelihoods, particularly when they disrupt local systems that have functioned well for centuries and that do not require improvement. They also warn of the potential threat of a narrowed gene pool to food security of human beings. In
China, the national government has promoted rural livestock breed improvement since the 1950s as an important part of the modernization of animal husbandry, although with limited success (Li and Li 2010).

In this paper, we will address two questions from the perspective of SES resilience: (1) what impacts on the rangeland SES have been caused by the government's interventions through livestock breed improvement? (2) How have the interventions come into effect?

\section{METHODOLOGY}

\section{Case study areas}

We have divided the history of China's livestock breed improvement efforts into three periods: the traditional, collective, and present (market economy) periods. This division was mainly based on the differences in rangeland management that resulted from national politics and economic conditions during the corresponding periods. We then obtained relevant data from each period through a literature review and field surveys. We reviewed official files, government documents, and academic publications to collect information about livestock breed improvement during each period, the corresponding institutional arrangements, and the market environment. Field surveys were carried out through household interviews from July to October 2008 and from June to July 2009 in 35 households of the Chifeng Municipality, in the Hexigten Banner. In Inner Mongolia, a "Banner" is the administrative equivalent of a county. We also interviewed 14 households in the Sonid Left Banner of the Xilingol League (administratively equivalent to a municipality) and 29 households of the Alxa Left Banner of the Alxa League (Fig. 1). In addition, we returned to the Hexigten Banner in July 2010 to carry out a follow-up field survey with some of the same interviewees from 2008.

Fig. 1. Locations of the case study sites. ALB = Alxa Left Banner; HB = Hexigten Banner; SLB = Sonid Left Banner.

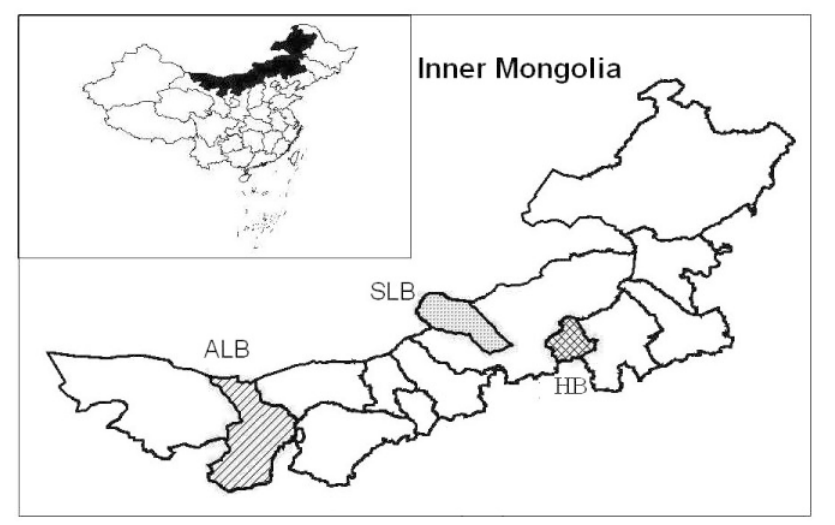


Table 1. The basic natural and socioeconomic characteristics of the three case study sites.

\begin{tabular}{|c|c|c|c|}
\hline & Hexigten Banner & Sonid Left Banner & Alxa Left Banner \\
\hline \multicolumn{4}{|l|}{ Natural environment } \\
\hline Vegetation types & $\begin{array}{l}\text { Forested grassland and typical } \\
\text { steppe }\end{array}$ & Desert grassland & $\begin{array}{c}\text { Desert grassland and desert } \\
\text { substeppe }\end{array}$ \\
\hline Annual precipitation & 350 to $400 \mathrm{~mm}$ & 165 to $215 \mathrm{~mm}$ & 64 to $208 \mathrm{~mm}$ \\
\hline \multirow{2}{*}{ Average temperature } & Annual: $0^{\circ} \mathrm{C}$ & Annual: $2.7^{\circ} \mathrm{C}$; & Annual: $7.4^{\circ} \mathrm{C}$ \\
\hline & January: $-21.5^{\circ} \mathrm{C}$ & January: $-20^{\circ} \mathrm{C}$ & January: $-11.6^{\circ} \mathrm{C}$ \\
\hline \multicolumn{4}{|l|}{ Social environment } \\
\hline Nationality & Han, Mongolian & Mongolian & Mongolian \\
\hline Mode of animal husbandry & $\begin{array}{l}\text { Livestock grazing combined } \\
\text { with agriculture }\end{array}$ & Grazing & $\begin{array}{l}\text { Grazing combined with } \\
\text { farming }\end{array}$ \\
\hline Main livestock species & Sheep, cattle & Sheep, goats, cattle & Sheep, goats, camels \\
\hline
\end{tabular}

To collect information for the collective period (from 1957 to 1982), we mainly interviewed herders in the Sonid Left Banner and Alxa Left Banner who raised exotic fine-wool sheep during that period and old Communist Party cadres who served in gacha ("village" in the Mongolian language) and related government agencies. Our investigations of sheep improvement during the most recent period (since 1983) were mainly conducted in the Hexigten Banner, because the Sonid Left Banner and Alxa Left Banner stopped improvement efforts after 1983. We interviewed households that raised exotic and native breeds to compare their experiences. We obtained information on the traditional period (before 1956) mostly from publications, supplemented by interviews with the elder herders. Because these three case studies reflect information from different periods, they should not be compared directly; instead, we have used them to form an overall picture of the history of livestock breed improvement in Inner Mongolia.

Inner Mongolia lies in a temperate continental climate zone. The rainfall is scarce and unevenly distributed both spatially and temporally. Various natural disasters, including drought, severe snowstorms, and sandstorms, occur frequently. The herders depend heavily on their livestock to earn a living. Table 1 summarizes the basic natural, social, and economic features of the three banners we surveyed.

\section{Analytical framework}

To explore the effects of the government's interventions in livestock breed improvement on the rangeland SES, we considered livestock breed improvement in the context of the animal husbandry system, and analyzed the relationship between them (Fig. 2). In rangeland, the livelihoods of the herdsmen depend strongly upon livestock, which in turn are highly dependent upon the available forage resource. Resource availability, livestock, and human users thus form an integrated rangeland system that can be represented by the coupled system in Figure 2. Outside this system, the natural ecological context at a broader scope influences the ecological processes inside the rangeland SES, and the socioeconomic context, i.e., the government and the market, affect herder behavior. Given the interactions between the production system, the natural ecological environment, and the pastoral society, we analyzed how the overall rangeland SES is affected by livestock breed improvement. We focused on the interactions and feedbacks among the components of the system, and especially on the coupling between natural and social systems. In arid and semiarid rangeland, the primary production is low and highly variable, so herder livelihoods depend strongly on the availability of natural resources and adaptation of the social system to the ecological system, and strongly functional feedbacks between the two are critical for the system's self-organization, i.e., for its resilience.

Fig. 2. The analytical framework used in our study.

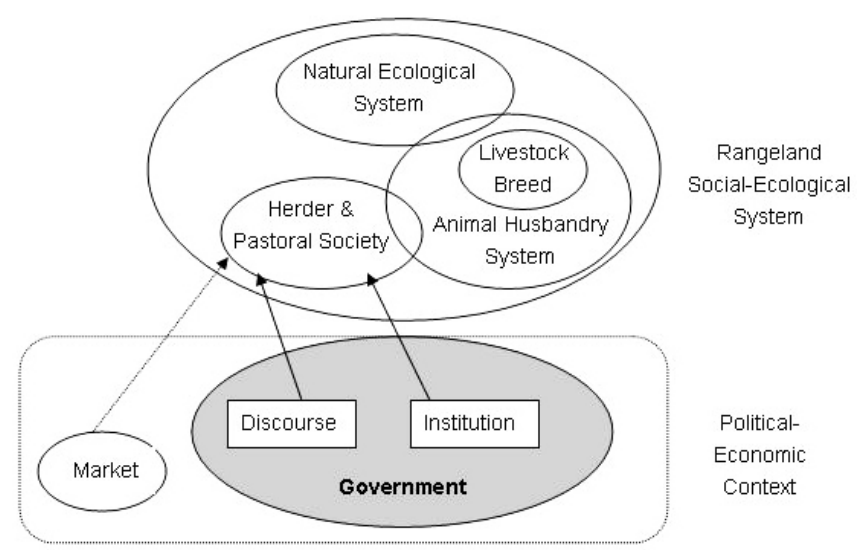

To analyze how the interventions of the external government affect the local community, we need to understand the multifaceted nature of government interventions. As Figure 2 shows, both institutional interventions and discourse are the main approaches by which governments promote livestock 
breed improvement. Here, we refer to institutional intervention as the government's efforts to change local management practices through formal institutions, whether political, economic, or administrative. The idea of introducing discourse into our analysis comes from Clement (2010), who incorporated discourse analysis within the traditional institutional analysis framework to explain how political and economic factors affect the rules that govern how the commons are managed by a community. In his paper, Clement defined discourse as "A specific ensemble of ideas, concepts, and categorizations that is produced, reproduced, and transformed in a particular set of practices and through which meaning is given to physical and social realities" (Hajer 1995, as quoted by Clement 2010:138). In our paper, we used Clement's definition, but with an emphasis on the external forces that manipulate the discourse to shape the beliefs, values, and cognition of pastoralists and that therefore modify their behavior. This discourse includes both propaganda and political movements that implement a particular philosophy, e.g., communes.

Although we focus on government interventions, the market is also an external force that influences animal husbandry outputs, i.e., production, by pastoral households and the pastoral society. We have therefore considered the market as a background that has changed greatly during the study period in China.

\section{RESULTS}

\section{Pastoral society and livestock breed management during the traditional period (before 1956)}

During the traditional period, the rangeland SES was relatively closed to outside social forces. Herders grazed livestock mainly to sustain their daily life. Occasionally, they exchanged wool and leather for products from agricultural areas, such as grain, tea, and handcrafts. Accordingly, the overall Chinese market had few effects on the pastoral society. The influence of external governments was also relatively weak. Pastures were owned by Mongolian nobles, but were collectively used by all the herdsmen. The livestock were private assets of each family. The state's power seldom penetrated the local society of the pastoral areas. Herders made good use of pastures by managing their livestock, with only rare influences by the external government and market (Wang 2006).

In such a closed system, the socioeconomic system and the natural system were closely connected, and social and economic activities were organized to adapt management to the constraints imposed by the natural environment. Mobility was the core of this SES. Herders drove their animals to track better forage and water and to escape the region's frequent natural disasters. They usually owned a range of animals, for example, horses, cattle, sheep, goats, and camels, so they could take advantage of different habitats, meet the different demands of daily life, and disperse risks. Because of the relatively low rate of natural increase of the human population imposed by the harsh environment, labor was in short supply. Accordingly, herders employed an extensive rather than intensive mode of animal husbandry. They raised animals that did not need much care, and they rarely constructed infrastructures such as shelters. To cope with the labor shortage and natural disasters, pastoralists set up a khot-ail system (a union of several individual households). Khot-ail households camped and traveled together, and cooperated on labor-intensive tasks such as cutting hay, making felt, and seasonal migrations (Bold 1996, Fernandez-Gimenez 1999). In many cases, the khot-ail functioned as a form of social safety net, allowing poor households to benefit from the assistance of wealthier households in an informal exchange for their labor (Fernandez-Gimenez 1999).

Natural disasters were the main interruptions to the grazing system (Yu 2003), and often led to serious animal mortality (Wang 2006). Immediate relocation to a new area (otor) was the most basic strategy used to defend against adverse climate during the traditional period (Xie and $\mathrm{Li}$ 2008, $\mathrm{Li}$ and Huntsinger 2011). In addition, wolf attacks and diseases threatened livestock. In such a harsh environment, the features of the livestock were essential for their survival. Livestock had to be able to adapt to the harsh natural environment, i.e., the prolonged cold and the reduced forage availability in winter, to move fast over long distances, resist diseases, escape predators, and survive with little care.

In the animal management process, herders often selected livestock based on their daily needs and production conditions. They considered characteristics such as physical features, fecundity, production of useful products, e.g., meat, milk, wool, and ability to survive natural disasters (Qi 2002). Considering physical features, for example, herders selected livestock with certain features to facilitate management. Most Mongolian sheep have black faces because herders cannot easily see sheep with white faces during the day in pasture with bare patches of exposed sand that reflects sunlight, and the black faces were also more visible in flourishing grasslands (Huan 1952). Culture also affected livestock choice. For example, herders in the Alxa Left Banner usually included a red goat in their herd because they believed that a red goat brought good luck to their family. The Animal Husbandry Chronicles of Xilingol League (Qi 2002) recorded preferences for livestock appearance in different parts of the Xilingol League. Herders selected excellent male and female individuals from native herds, and mated the best with the best to obtain livestock with better performance. In addition, during the transhumance, i.e., the seasonal move between pastures, they often exchanged male livestock with other communities to prevent inbreeding.

Some traditional customs promoted exchanges of livestock genes and optimization of the livestock gene pool. Highquality animals were usually exchanged as gifts. For example, 
the nobles often exchanged strong male livestock, beautiful female livestock, or a ewe and its lamb as gifts (Qi 2002). Livestock was included as part of engagement gifts and marriage dowries. In addition, some activities like the Nadam Fair (a traditional Mongolian festival) and religious activities such as $o b o$ sacrifices provided opportunities to exchange livestock (Qi 2002). Such exchanges not only improved the livestock breeds but also helped to sustain social relationships.

In addition to conscious selection, the harsh environment also subjected the livestock to natural selection. Individual livestock that could not adapt to their environment and that could not escape diseases and predators were eliminated, and the quality of the surviving livestock improved after a long period of the resulting evolution.

Because of significant differences in the natural environment and culture, herdsmen in different regions preserved various high-quality indigenous livestock breeds, such as Uzhumuchin cattle, sheep, and goats, Sonid sheep and goats, and Alxa cashmere goats and two-humped camels. The Reports on Livestock and Poultry Breed Resources in Inner Mongolia Autonomous Region recorded 34 high-quality indigenous breeds (LBISOIMAR 1983). These livestock were well adapted to the rigorous local natural environment and the extensive management (grazing) conditions. They also satisfied the herdsmen's multiple needs for living. These genetic resources played an important role in the pastoral society's ability to adapt to its challenging environment.

In summary, the pastoral society during the traditional period had a relatively isolated and self-sufficient natural economy. Herders grazed their livestock by tracking the change in forage resources, and provided few additional inputs. Their livestock management was rarely influenced by external political and economic factors. They usually maintained diverse, highquality breeds through selection of the native livestock, and improved the animals through exchange mechanisms based on social networks. In such a social-ecological system, adapting to the constraints of the natural environment was the basic principle that guided modes of livestock production and the organization of the pastoral society, and the adaptability of native animals played an important role in integrating the pastoral society with its harsh environment. Consequently, the social system was closely nested within the natural system and each component within the system formed tightly coupled relationships with other components.

\section{Pastoral society and livestock breed improvement during the collective period (1957 to 1982)}

During the collective period, in rural China as a whole, a centrally planned economy was implemented, and all means of production and products were required to be put under the collective, i.e., the "people's commune." Pastoral areas of Inner Mongolia started to establish people's communes in
1957 and since then pastoral areas have been integrated within the national economy. During this period, pastoral areas played a significant role in providing meat and dairy products and raw materials for the wool and leather industry to the whole country. The state controlled commodity circulation through planned supply and marketing networks. Local communities were required to arrange their production according to the tasks assigned by higher levels of government. The materials and means of production, such as livestock feed, machinery, and veterinary services, depended entirely on the state's supply and marketing channels. In this way, the economy, politics, and administration of the pastoral areas were forced to connect with the outside world.

Hierarchical relationships created the most significant characteristics of this system. During the collective period, all the members of a community collectively owned the pastures (Party Committee of Inner Mongolia 1961). The people's communes and the brigades (the lower level of production organization under the communes) shared management rights for the pastures, and the brigades owned most of the livestock. However, the higher levels of government, e.g., Banner level, League level, or even higher, actively interfered with the lower levels by imposing plans, commands, and tasks to enforce their management rights over pastures and livestock. At the lowest level, the production brigades were required to fulfill the tasks assigned by higher levels, which could be very specific, and one such task was livestock improvement. The labor within each brigade was organized and managed through a workpoint system that regulated labor requirements and remuneration within the brigade. The cadres of each commune and brigade arranged its production activities, and pastoralists implemented the arrangements. In such a top-down system, the government closely controlled the grass roots activities of the pastoral society. The pastoralists and the communities had limited channels to participate in the decision making processes.

Animal husbandry was politicized during the collective period. Increased output of livestock products was taken as the only goal of livestock husbandry in pastoral areas, and this was connected with political discourse in the form of goals such as supporting the national economy and serving the people of the whole country. Under the ideology that humans can conquer nature, the traditional backward pattern of nomadic animal husbandry was to be replaced by modern intensive animal husbandry, with the goal of eliminating the constraints imposed by the natural ecological environment. These ideas created a kind of discourse that deeply influenced the thinking of pastoralists, and was used as an instrument by the governments to reorganize and mobilize pastoral society.

Under the guidance of this ideology, the governments encouraged and helped pastoralists to construct infrastructures, 
and provided related services, such as building pens, drilling wells, cutting and storing hay, providing veterinary services, hunting wolves, planting forage, and encouraging the formerly nomadic pastoralists to settle down. Through these interventions, the mode of traditional livestock husbandry changed from one that completely adapted itself to the natural environment to one that attempted to ignore that environment and depended increasingly on external inputs. The constraints of nature on animal husbandry were relieved to some degree, and planting forage, storing silage, and building shelters gradually displaced the traditional strategy of mobility as a way to cope with natural disasters. However, labor shortages remained a problem.

Livestock breed improvement was chosen as one of the important steps to achieve so-called "animal husbandry modernization," so the governments specified that this was one of the main tasks in animal husbandry. For example, the fifth volume of Selected Documents on Animal Husbandry in Inner Mongolia (Chen 1986) assembled 104 documents and notifications about animal husbandry from 1949 to 1985 that were issued by the Inner Mongolia government; of these documents, $45 \%$ were about livestock breed improvement.

At that time, various levels of government introduced a variety of rams of sheep breeds that produced fine and semifine wool and of Karakul sheep to hybridize with local breeds through artificial insemination. Supporting the national macroeconomic strategy was the core concern in selecting these breeds. For example, changing from the indigenous Mongolian sheep to the wool-producing breeds was implemented to support the domestic wool industry, and the Karakul breed was mainly raised for export to obtain foreign exchange.

Livestock breed improvement was taken as a political task, and was organized through administrative orders from the central government to local governments. For example, the Animal Husbandry Chronicles of Xilingol League (Qi 2002:371) reported that,

In 1958, the Ministry of Agriculture proposed a political call "headed by the party secretary, mobilizing the whole party, overall promoting sheep breed improvement." Consequently, the Party Committee of Inner Mongolia Autonomous Region assigned a task to the Xilingol and Chahar leagues to improve 740000 sheep. In October of that year, when these two leagues were merged, the League Commission announced a decision to strengthen the leadership in livestock production in which sheep improvement was taken as a glorious but arduous political task that must be completed. In 1958, an additional 1325 studs from sheep breeds that produced fine wool were allocated to these leagues, even though they already had 363 studs, and 596 sets of artificial insemination equipment, 50 microscopes, and a budget of 13120 RMB for auxiliary equipment were allocated by the Inner Mongolian government.

From the perspective of organizational arrangements, the higher levels of government encouraged the communes to establish artificial insemination stations. In 1956, 266 artificial insemination stations for sheep were established in Inner Mongolia by the communes (Chen 1986). From the perspective of human and material resources, the governments were responsible for providing high-quality studs, artificial insemination equipment, and extra feed for the studs, as well as training for artificial insemination technicians. From the financial perspective, banks were required to offer loans to support investments by the communes in livestock breed improvement, such as purchasing studs and equipment (Chen 1986). The commune and brigade leaders were required to develop their own livestock breed improvement plans and ensure that these plans were implemented. In addition to plans and tasks, communes used competitions, commendations, and other political means to encourage the brigades to improve their livestock.

However, government records and our field investigations showed that the 'improved' animals and exotic breeds were much less able to adapt to the local ecological environment than the indigenous animals. The improved lambs had a lower survival rate during cold weather, cost more to feed because extra fodder and forage were required, and required more labor, especially when delivering lambs. An old woman, a pastoralist from Sonid Left Banner, described this as follows: "The survival rate of fine-wool lambs was particularly low, since they were not adapted to the local climate. Sonid [native] lambs could walk while their mothers grazed within 2 days after they were born, whereas fine-wool lambs needed a month. And they were vulnerable to diseases and had to stay in sheep pens and be kept warm using quilts." An old woman who was assigned to raise fine-wool sheep during the collective period told us: "I couldn't go to sleep when they [fine-wool sheep] were giving birth, because I was afraid the lambs might freeze to death. If there were too many deaths, the brigade would ask me to pay for the dead lambs. In contrast, herders who raised Sonid sheep felt much more relaxed, since they didn't need to keep watch and care for the newborns all night." In addition, the improved breeds had difficulty traveling long distances between pastures when this was necessary.

In addition, raising some exotic breeds conflicted with the traditional culture. For example, to meet market demands, Karakul lambs were supposed to be slaughtered within seven days after birth to harvest the fur, and this was inconsistent with the Mongolian tradition of caring for young animals. Some pastoralists told us that "Mongolians cherish young 
animals, and that when we were required to kill 7-day-old Karakul lambs, we felt pity for these tiny lives and were reluctant to do so."

Despite the fact that the improved sheep were unsuitable for the ecological environment and ethnic cultural traditions, governments continued their goals to sustain the national economy and modernize animal husbandry, and took all measures possible to promote livestock breed improvement, including controlling material inputs, rearranging institutions, and reshaping the thinking and understanding of pastoralists. Compared with the traditional period, the construction of warm sheds increased the survival rate of the improved sheep, and accommodated the decreased mobility of the exotic species that were not accustomed to long-distance movement. In addition, the improved veterinary services made the natural resistance of livestock to disease less important.

From the perspective of institutional arrangements, the increased labor demand created by the use of improved breeds was met by applying incentive policies. Those who raised improved sheep were supposed to receive more work points, and the required lamb survival rate was decreased slightly. For example, in one brigade in the Hexigten Banner, the herders responsible for taking care of newborn improved lambs received 17 work points and received a bonus if the survival rate exceeded $80 \%$. In contrast, herders in charge of native lambs only received 13 work points, and only received a bonus when the survival rate exceeded $90 \%$ (Hexigten Banner Archives, unpublished data). In addition, some enforcement measures were implemented. For example, an old cadre from Alxa Left Banner told us that "At that time, political factors significantly promoted livestock breed improvement. A pastoralist was once criticized and persecuted just for saying that the exotic rams were not good under local conditions." From the perspective of cognition, all levels of government repeatedly stressed the importance of livestock breed improvement, and the cadres were required to make the pastoralists realize the importance of improved sheep through education and propaganda. Livestock breed improvement was connected to propaganda slogans such as the need to support national construction and modernize the animal industry.

Under the government's efforts, the number of improved sheep in Inner Mongolia increased year by year. For example, in Sonid Left Banner, sheep of improved breeds increased from $0.29 \%$ of the total in 1958 to $38.92 \%$ in 1981 ; during the same period, the proportion increased from $0.8 \%$ to $52.03 \%$ in 1981 in Sonid Right Banner (Sambu 1981). However, the improved sheep were not adapted to the local natural environment. In the early 1980s, once herders regained the right to choose their own livestock, they immediately stopped the sheep improvement that had been promoted by Inner Mongolia's government for more than 20 years, and started to phase out the improved livestock by backcrossing them with native rams.
In summary, the collective period represented a time when the traditional pastoral society was incorporated into the Chinese planned economic system, and local communities had little chance for self-determination in managing their resources. Under the goals of supporting the national economy and modernizing animal husbandry, and the associated discourse, the governments introduced material inputs into livestock production to redesign the mode of animal husbandry and promoted livestock breed improvement to meet the needs of national economic construction through administrative commands, economic plans, and political mobilization, i.e., discourse. However, because the new animals could not survive the region's harsh conditions, the production conditions were reformed in an effort to relieve natural constraints, and the pastoral society was reorganized to support the national desire for improved breeds. These measures radically changed the mode of animal husbandry, which was increasingly separated from the natural environment and more strongly connected with the external world through a centralized economy.

\section{Present pastoral society and livestock breed improvement (after 1983)}

In 1983, the Household Responsibility System was implemented in China's rural areas. China's economic system simultaneously turned from a centrally planned economy toward a market economy. Communes were dissolved. Production materials were distributed to individuals, and a household-based production system was established. Pastoralists gained complete ownership over their herds in the early 1980s and gained usage rights to a parcel of pasture and the right to benefit from it in the mid- and late 1990s. Administrative power and political factors became weaker influences on the daily animal husbandry operations of pastoral households. Since then, pastoralists have been allowed to make their own decisions on management of their rangeland and livestock. During the change to a market economy, pastoralists gradually became more involved with national and local markets. Simultaneously, pastoral areas lost their dominance in supplying livestock products for the country because of rapid expansion of intensive animal husbandry in agricultural and semipastoral areas. However, livestock husbandry remained the major source of income for most pastoralists in pastoral areas.

After 2000, ecological degradation that resulted from a combination of climate change and unsustainable management practices was recognized as an increasingly serious problem, and governments at several levels started to intervene again in the daily production of pastoral households through the implementation of a series of ecological policies and projects. The word ecology became part of mainstream discourse in pastoral areas (Xun 2009, Yeh 2009). However, the goals of increasing commercial output and marketization became another dominant part of the discourse. The 
improvement of pastoralist livelihoods was thought to be equivalent to increasing their monetary income.

After decades of outside intervention, the current mode of production had become very different from that in the traditional era. As pastoralists settled down and rangeland contracted to the land allocated to individual households, the traditional mobility of livestock almost disappeared. External inputs such as building warm barns and shelters further alleviated the stress on the animals from the natural environment, especially during the brutal winters. Pen-raising and importing feed became the main strategy for coping with natural disasters. Simultaneously, populations of wild animals decreased greatly, and the serious problem of wolf attacks, which were frequent during the traditional period, was no longer a problem. As a result of these changes, the ability of livestock to adapt to the natural environment was less important than it used to be.

From an institutional perspective, villages (gacha) rarely interfere with an individual's animal husbandry operations, so there were no restrictions at a collective level on decision making regarding livestock selection. Herders sell old and weak animals for cash, keep good females as reproductive materials, and keep or purchase good males to improve their herds. Purchasing these males becomes the only way to refresh the gene pool of a herd because long-distance mobility is no longer practiced, i.e., there are fewer opportunities to meet herders from other regions, and livestock are no longer exchanged as gifts. Most herders buy breeding males from nearby communities through social networks. A few people buy high-quality males, especially improved breeds, from traveling dealers or formal livestock markets, but this is expensive and beyond the means of many pastoralists.

Because overgrazing is believed to be a dominant factor responsible for rangeland degradation, decreasing the number of livestock has become a government priority and their primary solution to the region's ecological problems. Because herder income will decline under this policy, governments have launched a new round of livestock breed improvement programs with the expectation of reducing quantity while improving quality. The government imported a large quantity of exotic sheep for meat production, such as Suffolk and Poll Dorset. In contrast with the breeds imported during the collective period, which were mainly chosen for their ability to produce fine wool, these breeds have been selected because of their higher meat output to meet the growing market demand for meat.

During the current period, governments have adopted incentive mechanisms rather than the former command-andcontrol approaches used during the collective period to promote livestock breed improvement. In the Hexigten Banner, the local government employs both administrative and economic incentives. The government shortened the period during which grazing is forbidden for those who raise improved livestock. Under the Grazing Ban Policy that has been strictly enforced in Inner Mongolia since 2003, penraising is required instead of grazing throughout the year in this area. However, if herders participate in a livestock breed improvement program, they are allowed to graze their livestock on natural rangeland from May to the middle of October, which can reduce the considerable cost of penraising. Furthermore, from the perspective of animal behavior, exotic breeds are better adapted to pen-raising than native animals, therefore this provides an incentive for herders to raise exotic breeds under the grazing ban.

In addition to this policy incentive, governments also employ economic incentives to encourage livestock breed improvement. Subsidies are provided to cover the extra cost for herders who participate in this program, such as providing construction materials or financial support for building warm barns and shelters or silage tanks, providing fodder grinders, providing low-interest loans so herders can purchase breeding females and studs of exotic breeds, or directly giving breeding females to the herders. In addition, mainstream discourse has been used to shape cognition. The ecology discourse, i.e., protecting the regional environment, has helped to legitimize the government's policy of decreasing the livestock population. Through other propaganda, governments have tried to convince herders that improved breeds perform better and provide a higher economic return.

In terms of the adaptive ability of the exotic breeds, the problems remain the same as those during the collective period: the exotics have lower resistance to cold, require more forage, and require more labor, particularly to take care of the lambs. To mitigate these problems, more warm barns and shelters have been built, relocation of the animals has been discouraged, and more grassland has been cultivated to produce forage. All these approaches aim to make the livestock's ability to adapt to the local environment less important. Simultaneously, as herders become increasingly involved in the market economy, herders have begun to consider commercial output as a primary consideration in livestock performance.

In such a context, herders have developed ambivalent attitudes toward livestock breed improvement, as revealed in our interviews. On the one hand, they complain that the exotic breeds are not adapted to the environment and need more feed and labor. For example, some herders told us they would prefer to raise native fat-tail sheep instead of improved breeds because the improved sheep eat too much, and both the adults and the lambs need grain for supplemental feed. In addition, the exotics cannot tolerate the cold. In contrast, the native animals are much easier to raise because they are more flexible in their food choices and resist the cold better. The herders also told us why they sometimes adopted improved breeds, as 
Table 2. Socioeconomic context for livestock breed management and improvement during the three study periods.

\begin{tabular}{|c|c|c|c|}
\hline & $\begin{array}{l}\text { Traditional era } \\
\text { (before 1956) }\end{array}$ & $\begin{array}{l}\text { Collective period } \\
\text { (1957 to } 1982)\end{array}$ & $\begin{array}{l}\text { Present } \\
\text { (after 1983) }\end{array}$ \\
\hline Economic system & Subsistence economy & Planned economy & Market economy \\
\hline $\begin{array}{l}\text { Purposes of animal } \\
\text { husbandry }\end{array}$ & Sustain household livelihood & $\begin{array}{l}\text { National demands for wool, } \\
\text { leather, meat, and dairy products }\end{array}$ & Commercial output \\
\hline Mainstream discourse & Adapt to nature & $\begin{array}{l}\text { Support national construction, } \\
\text { modernization }\end{array}$ & $\begin{array}{l}\text { Modernization, ecological protection, } \\
\text { increase herder income }\end{array}$ \\
\hline Mode of animal husbandry & Transhumance & $\begin{array}{l}\text { Transhumance supplemented } \\
\text { with feed, primary veterinary } \\
\text { services, and warm shelters }\end{array}$ & $\begin{array}{l}\text { Grazing within fenced individual } \\
\text { grasslands, complemented by pen- } \\
\text { raising, depending heavily on } \\
\text { supplementary feeding, veterinary } \\
\text { services, and warm shelters }\end{array}$ \\
\hline Imported breeds & None & $\begin{array}{l}\text { Sheep with high performance in } \\
\text { wool production }\end{array}$ & $\begin{array}{l}\text { Sheep with high performance in meat } \\
\text { production }\end{array}$ \\
\hline $\begin{array}{l}\text { Government approaches to } \\
\text { promote livestock breed } \\
\text { improvement }\end{array}$ & No governmental intervention & $\begin{array}{l}\text { Financial and material inputs, } \\
\text { political mobilization, } \\
\text { administrative command and } \\
\text { control, central economic plans }\end{array}$ & $\begin{array}{l}\text { Policy and economic incentives, } \\
\text { propaganda }\end{array}$ \\
\hline $\begin{array}{l}\text { Management of improved } \\
\text { breeds }\end{array}$ & $\begin{array}{l}\text { Selection within native } \\
\text { animals, exchanges of superior } \\
\text { animals through social } \\
\text { networks }\end{array}$ & $\begin{array}{l}\text { Exotic breeding males imported, } \\
\text { artificial insemination, increased } \\
\text { input from outside }\end{array}$ & $\begin{array}{l}\text { Exotic breeding males and females } \\
\text { imported, increased demand for outside } \\
\text { input }\end{array}$ \\
\hline $\begin{array}{l}\text { Result 1: } \\
\text { Livestock breeds }\end{array}$ & $\begin{array}{l}\text { Diverse native breeds, well } \\
\text { adapted to the environment }\end{array}$ & $\begin{array}{l}\text { Considerable loss of native } \\
\text { genetic resources, herders } \\
\text { resistant to improved breeds }\end{array}$ & $\begin{array}{l}\text { Many native genetic resources lost. } \\
\text { Herders choose to raise improved } \\
\text { breeds, passively or actively, under } \\
\text { new government policies and economic } \\
\text { incentives }\end{array}$ \\
\hline $\begin{array}{l}\text { Result 2: Relationship } \\
\text { between social and } \\
\text { ecological systems }\end{array}$ & $\begin{array}{l}\text { Social system embedded in the } \\
\text { ecological system }\end{array}$ & $\begin{array}{l}\text { Animal husbandry began to } \\
\text { detach from the ecological } \\
\text { system }\end{array}$ & $\begin{array}{l}\text { The social system is increasingly } \\
\text { separating from the ecological system } \\
\text { and trying to control it. }\end{array}$ \\
\hline
\end{tabular}

promoted by the government. They felt it was necessary to adopt these breeds to meet government demands, particularly since native animals are not allowed to graze outside pens and it is not feasible to raise them in pens in the long term.

On the other hand, the herders also admired the higher output of the improved breeds. The lambs are heavier and their wool is worth more in the market if the conditions required for production of these animals can be met. In general, herders now pay more attention to economic value than to the ability of the animals to adapt to the natural environmental and production conditions. This reveals that a change in the pastoral social norms has been taking place.

During the marketization period, the herders superficially gained management rights over rangeland and livestock and became deeply involved in the market economy. Ecological protection and restoration, modernization of animal husbandry, and increasing herder income became the dominant discourse that shaped the cognition of governments and herders. In the name of protecting the ecological environment and increasing herder income, the governments imported exotic breeds and encouraged pastoralists to adopt these breeds, thereby continuing to reconstruct the traditional mode of animal husbandry. Traditional nomadic practices nearly disappeared, and animal husbandry relied increasingly heavily on outside inputs, with the production mode gradually changing to meet the needs of the improved breeds. As part of this adaptation process, herders are gradually accepting improved breeds. Simultaneously, the animal husbandry system is being reorganized to meet external market and 
government demands. The philosophy and norms of the herders are increasingly adapting to those of the external world instead of the needs of their local rangeland SES. Consequently, the rangeland SES is transforming from a closely coupled system in which the social system adapted to the natural system, to an approach in which the social system is separating from and trying to conquer the natural system. On the other hand, the decoupling of the natural and social components of the local SES is being accompanied by increased connectivity with the external world, especially in the social sphere, as herders become more fully involved with the market and better adapted to strong governmental interference with local practices. The influence of this increased external connectivity on the resilience of the local SES has yet to be explored. However at least from the perspective of herders' income, it is not optimistic. It is well known that in the past the average income of herders had been much higher than farmers in Inner Mongolia until at least 1980. Given the rapid economic growth of China as a whole, and although the present income of herders has increased fivefold (Dalintai and Zheng 2010) compared with the collective period, herder income is however still lower than farmers and even presents a decreasing trend. This was identified by the government as the most important and urgent issue in their No. 1 document of 2010, Opinions on the Implementation of Accelerating Income of Herders, issued by Government of Inner Mongolia Autonomous Region (2010). To facilitate comparisons of the three periods, Table 2 summarizes the details of each period.

\section{ANALYSIS AND DISCUSSION}

\section{Impacts of livestock breed improvement on the rangeland SES}

Reviewing the history of livestock breed improvement management revealed that livestock breed was clearly the key element that connects the pastoral society of Inner Mongolia, through its livestock production system, with the ecological environment (Fig. 2). Changing the local breed, e.g., adopting exotic breeds, therefore means changing the production system and its relationship with its environment. By promoting livestock breed improvement, the local and national governments have also created a new series of inputs into this system by building pens and warm shelters, drilling wells, cultivating grassland, and planting artificial forage, among other actions. These inputs, together with livestock breed improvement, represent systematic interventions to establish intensive animal husbandry. In the pursuit of higher economic output, the region's forage resources, labor resources, and social institutions have been rearranged. As a result, the animal husbandry system has experienced dramatic transformations, leading it to increasingly rely on outside inputs and gradually separating it from the natural ecological system. Changes in production modes also led to changes in the rangeland management institutions, both formal rules and informal customs and norms, further weakening the coupling between the production and ecological subsystems. The rangeland SES has transformed from a coupled system in which the social system adapts, as needed, to the natural system, to a decoupled system within which the social system is separate from and trying to control the natural system.

During such a process, serious ecological problems can arise, such as overgrazing of sites due to the decreased mobility that resulted from adopting a sedentary lifestyle (Zhang and $\mathrm{Li}$ 2008), the loss of livestock genetic diversity due to the adoption of a small number of high-performance breeds with narrower genetic diversity, and excessive rangeland reclamation and exploitation of underground water due to the planting of forage crops (Erdunbuhe 2004). The roots of such problems lie in uncoupling certain key elements of the rangeland SES. However, recent ecological policies such as the grazing ban, ecological emigration, and intensification of animal husbandry promoted by the government to deal with these problems do not aim to reconnect these interactions, but instead further widen the separation. In practice, these projects are oversimplified because they consider only individual elements of the rangeland SES without accounting for important interactions among the elements and because they do not consider the complex relationships between human beings, the region's grassland ecosystem, and the livestock.

\section{How interventions come into effect}

By comparing livestock breed improvement practices between the collective period and the present approach, we can see many similarities (Table 2) despite huge differences in the political and economic contexts. That is, in both of the most recent periods, herders raise livestock according to external demands, i.e., the state's demands in the collective period and the market's demands currently, instead of based on their own needs, as was the case during the traditional era. The region's and society's production resources have been reorganized to meet these new demands. For example, it has become necessary to plant or import forage to meet the greater nutritional demands of the improved exotic breeds. Accordingly, external factors have increasingly dominated livestock breed improvement and management in Inner Mongolia. There has been general agreement in the research literature on common pool resource management that external interventions should be adapted to the needs of the target system, and should not crowd out and displace the original cooperative relationships that existed within the system and the human community, and that the relationship between governments and local communities should be complementary instead of displacing existing social structures (Agrawal and Gibson 1999, Bowles and Gintis 2002, Sanginga et al. 2007). Unfortunately, in the process of livestock breed improvement in the Inner Mongolian rangeland SES, the original relationships within the system have been increasingly disrupted by external factors. 
How does this kind of disruption take place? To explore this question, we should first realize that governments never promote livestock breed improvement in isolation; instead, they always combine such interventions with systematic reconstructions of the animal husbandry system. The constraints of Inner Mongolia's rigorous environment on exotic breeds must be handled through pen-raising, supplemental feeding in winter, and replacement of the traditional pattern of nomadic mobility with fixed settlements, thereby making it possible for exotic breeds to survive in this region. These interventions mutually reinforce each other, changing the production system as a whole toward increasingly intensive animal husbandry. Nevertheless, it is worth asking how these interventions are enforced in a pastoral society, and why local communities are willing to adjust their social system in response to such interventions.

The displacement of community authority by government authority has its roots in the power asymmetry between the national government and the local community. During China's collective period, the power asymmetry existed in political, administrative, and economic areas. The communities were integrated into the state's vertical management system in the context of a centrally planned economy and a centralized administrative system. From the perspective of Ostrom's (1990) institutional analysis and development framework, governments controlled the available choices at the collectivechoice level (where decisions affect rules at the operational level) and the constitutional level (where decisions affect rules at the collective-choice level) in economic, political, and administrative affairs; as a result, the community's ability to make decisions was limited to the operational level, and its choices were greatly constrained by rules made at the collective and constitutional levels. Therefore, the government could use the instruments of administrative command, central planning, and task assignments to promote livestock breed improvement in pastoral areas. During the modern market economy era, with a depoliticized production field, this power asymmetry is based more on economic and administrative aspects. On the one hand, governments have encouraged herders to raise improved breeds by loosening the grazing ban for these breeds. On the other hand, governments have provided considerable subsidies for herders willing to improve their livestock. Although herders own their livestock individually, and can make independent decisions about livestock management, they find it hard to resist the temptations of these administrative and economic incentives, and this has pushed many herders in the direction desired by the government, even though this direction is not suitable for the local ecological system in the long run.

Discourse is another factor that contributes to the displacement of community by the government. From the perspective of governments, livestock is nothing more than production material and products, and the value of livestock lies solely in their roles as economic outputs. The result has been a series of approaches designed to increase the outputs of animal husbandry while ignoring the complex interactions between livestock, humans, and the rangeland ecosystem, as well as the potential ecological impacts of pursuing output quantity as the only goal. Also, during the time of the centrally planned economy, increasing outputs were connected with politically charged meanings such as supporting national construction. Under the present market economy, increasing economic outputs for the benefit of individuals is a discourse that promotes the logic of the market. Simultaneously, livestock improvement has been portrayed as a representation of advanced science and technology. High-performance breeds imported from developed countries and the use of high-tech artificial insemination have been promoted in the name of economic development, advanced science and high technology, and modernization. In the mainstream of modern society, science is accepted without question as a virtuous thing, and modernization has similarly been adopted as a desirable pursuit. These areas of discourse legitimize livestock breed improvement. Under the influence of this discourse, governments take livestock improvement as a given. They then apply this discourse as an instrument to exert their power. They reconstruct herder cognition through propaganda, so as to rationalize their interventions. Power asymmetry may have had different influences during the collective period and the present, but its influence has nonetheless been significant in both periods. The increasing acceptance of improved breeds by some herders is affected and effected by such discourse.

\section{CONCLUSIONS}

Given the complexity of SES, efficient management of natural resources requires collaboration at multiple levels. Intervention from external governments has been a significant factor affecting how the local community uses and manages its resources, and may become an inevitable or even necessary part of common pool resource management. In this paper, we described the influences of various governmental interventions on the rangeland SES of Inner Mongolia during the last half century, and further explored the effects of such interventions and discussed how they occur. Based on case studies and a literature review for livestock breed improvement in Inner Mongolia, we showed that livestock breed improvement is not an independent strategy but rather is accompanied by systematic interventions that have impacts throughout the social, economic, and environmental systems. The interventions, combined with other technical interventions designed to intensify animal husbandry, have changed the production mode of local communities. Accompanied with changes in the socioeconomic context, these changes have increasingly uncoupled the livestock production system from the natural system that sustains it. These interventions resulted from an oversimplified logic that the value of livestock is only equated to its ability to generate 
meat and dairy products, and that intensive animal husbandry equates to an advanced civilization. This erroneous logic has increasingly detached livestock management from the rangeland SES and damaged the web of interactions among the many components of this complex rangeland system.

Simultaneously, the new cognition that has resulted from these interventions has formed discourse suites that have shaped the thoughts of the government and of the herders, and become the instruments by which the governments conduct their interventions in the rangeland SES. Because of the asymmetric power relationship between the national government and the local community, the government controls a disproportionate amount of the political, administrative, and economic resources, which facilitates its ability to implement its plans directly in the local community, as was the case during the collective period, or indirectly, as is the case in the present period. Under the combined impact of this discourse and the power asymmetry, governments have displaced communities from their traditional roles and dominated rangeland management, and consequently, the production system has been reorganized to meet external demands. Although the socialist centrally planned economic system and the capitalist market economy system are generally considered to be opposites, they shared many similarities in the present study in terms of their effects on the rangeland SES: the emphasis on maximizing commodity production for the external world, the enthusiasm for modern technology, and the pathology of natural resources management (Holling and Meffe 1996). Such features resulted from the ambition to control the rangeland ecosystem instead of adapting to it, guided by the single goal of increasing production and by a limited understanding of the true complexity of the rangeland SES.

Our results indicate that in the arid and semiarid rangelands of Inner Mongolia, the natural system is tightly coupled with the social system. In such a situation, external interventions with a single goal and with inadequate understanding of the complexity of the target system may have devastating consequences for the environment and the local culture. In addition, the value perspectives of the interveners and their discourse influence both their fellow interveners and those who experience the resulting interventions, and may determine the acceptance of these interventions.

Although we noted that government interventions may displace the local community from self-governance, such displacement does not inevitably occur. A strong government that is willing to adapt to the needs of the target system could organize and mobilize resources more efficiently than the local community, and this could result in more effective and efficient resource management. For example, during the collective period, it was the responsibility of the communes and of the banner governments to organize and help herders to conduct otor when natural disasters occurred, which greatly reduced animal losses (Xie and $\mathrm{Li}$ 2008, Li and Huntsinger
2011). Other studies have also shown that governments can play active roles in natural resource management by mediating conflicts that extend beyond the community level (Sanginga et al. 2007), by solving the problems of resource capture by certain elites (Sanginga et al. 2007), and by remedying inadequate informal sanctions (Bowles and Gintis 2002) within communities. Therefore, we argue that it does not matter whether government interference is strong or weak. What matters is whether the government fully understands the complexity of the target system, and is able to design interventions that meet the social, economic, and environmental demands of the target system.

Although we have emphasized the degree of coupling between the social and natural systems, we want to emphasize the local scale of such couplings. Although decoupling was emphasized at a local scale, i.e., the scale of the pastoral area in our paper, the rangeland SES may be increasingly coupled with the external world at regional, national, or even global scales. Decoupling could be expected to reduce resilience. Our case affirms this at the local scale. However, whether it is also true at the larger scale remains to be determined.

Responses to this article can be read online at: http://www.ecologyandsociety.org/voll7/issl/art9/responses/

\section{Acknowledgments:}

Research on this topic was supported by the National Natural Science Foundation of China (40871252) and a Ford Foundation grant. We thank Dr. Irene Bain of Ford Foundation for her stimulating ideas when we started to draft this paper, and two anonymous reviewers for their valuable comments and advice. We thank all the students in our team for their contributions to the case study analysis and for their discussion during our weekly group meeting. Special thanks go to all the hospitable Mongolian herders, who were always patient with our numerous questions.

\section{LITERATURE CITED}

Agrawal, A. 2003. Sustainable governance of common-pool resources: context, methods, and politics. Annual Review of Anthropology 32:243-262. http://dx.doi.org/10.1146/annurev. anthro.32.061002.093112

Agrawal, A., and C. C. Gibson. 1999. Enchantment and disenchantment: the role of community in natural resource conservation. World Development 27(4):629-649. http://dx.do i.org/10.1016/S0305-750X(98)00161-2

Ahuya, C. O., A. O. Mwai, D. Mwangi-Njuru, and C. Peacock. 2005. Developmental challenges and opportunities in the goat industry: the Kenyan experience. Small Ruminant Research 60(1-2):197-206. 
Anderies, J. M., M. A. Janssen, and E. Ostrom. 2004. A framework to analyze the robustness of social-ecological systems from an institutional perspective. Ecology and Society 9(1): 18. [online] URL: http://www.ecologyandsociety.org/vol9/ iss $1 / \operatorname{art} 18 /$

Ayalew, W., B. Rischkowsky, J. M. Kinga, and E. Bruns. 2003. Crossbreds did not generate more net benefits than indigenous goats in Ethiopian smallholdings. Agricultural Systems 76:1137-1156. http://dx.doi.org/10.1016/S0308-521X(02)00033-1

Benjamin, C. E. 2008. Legal pluralism and decentralization: natural resource management in Mali. World Development 36 (11):2255-2276. http://dx.doi.org/10.1016/j.worlddev.2008.03.005

Berkes, F., J. Colding, and C. Folke. 2003. Navigating socialecological systems: building resilience for complexity and change. Cambridge University Press, Cambridge, UK.

Bold, B. O. 1996. Socio-economic segmentation-Khot-Ail in nomadic livestock keeping of Mongolia. Nomadic Peoples 39:69-86.

Bowles, S., and H. Gintis. 2002. Social capital and community governance. Economic Journal 112:419-436. http://dx.doi.or g/10.1111/1468-0297.00077

Chen, J. R., editor. 1986. Selected documents on animal husbandry in Inner Mongolia. [NeiMengGu XuMuYe WenXian ZiLiao XuanBian]. Volume V. Policy Study Division of Communist Party Committee of Inner Mongolian Autonomous Region [NeiMengGu DangWei ZhengCe YanJiu Shi], Hohhot, Inner Mongolia, China.

Clement, F. 2010. Analysing decentralised natural resource governance: proposition for a "politicised" institutional analysis and development framework. Policy Sciences 43 (2):129-156. http://dx.doi.org/10.1007/s11077-009-9100-8

Clement, F., and J. M. Amezaga. 2009. Afforestation and forestry land allocation in northern Vietnam: analysing the gap between policy intentions and outcomes. Land Use Policy 26(2):458-470. http://dx.doi.org/10.1016/j.landusepol.2008.06.003

Dalintai and Y. S. Zheng. 2010. Pastoral areas and market: a herder-based economics. [MuQu Yu ShiChang: MuMin JingJiXue]. Social Sciences Academic Press, Beijing, China.

Erdunbuhe. 2004. A major cause for the desertification of grasslands-with the drastic desertification of Hulunbuir Grasslands as a case study. [Caoyuan Huangmohua De Yige Zhongyao Chengyin-Yi HuLun BeiEr CaoYuan HuangMoHua JiaJu WeiLi]. Journal of Inner Mongolia University (Humanities and Social Sciences). [Neimenggu Daxue Xuebao (Renwen, Shehui Kexue Ban)] 36(2):81-85.
Fernandez-Gimenez, M. E. 1999. Sustaining the steppes: a geographical history of pastoral land use in Mongolia. Geographical Review 89(3):315-342. http://dx.doi.org/10.230 7/216154

Folke, C., T. Hahn, P. Olsson, and J. Norberg. 2005. Adaptive governance of social-ecological systems. Annual Review of Environment and Resources 30:441-473. http://dx.doi.org/10 $.1146 /$ annurev.energy.30.050504.144511

Government of Inner Mongolia Autonomous Region. 2010. Opinions on the Implementation of Accelerating Income of Herders. [GuanYu Cujin MuMin ZengJia ShouRu De ShiShi YiJian]. Government of Inner Mongolia Autonomous Region, Hohhot, Inner Mongolia, China.

Holling, C. S., and G. K. Meffe. 1996. Command and control and the pathology of natural resource management. Conservation Biology 10(2):328-337. http://dx.doi.org/10.1046/ j.1523-1739.1996.10020328.x

Huan, Z. J. 1952. China's Inner Mongolia pastoral area. [Zhongguo De Neimeng Muqu]. Yongxiang Press, Shanghai, China.

Johnson, C. 2004. Uncommon ground: the 'poverty of history' in common property discourse. Development and Change 35 (3):407-434. http://dx.doi.org/10.1111/j.1467-7660.2004.00359. $\underline{\mathrm{X}}$

Kosgey, I. S., R. L. Baker, H. M. J. Udo, and J. A. M. Van Arendonk. 2006. Successes and failures of small ruminant breeding programmes in the tropics: a review. Small Ruminant Research 61(1):13-28.

Kosgey, I. S., G. J. Rowlands, J. A. M. van Arendonk, and R. L. Baker. 2008. Small ruminant production in smallholder and pastoral/extensive farming systems in Kenya. Small Ruminant Research 77(1):11-24.

Lebel, L., J. M. Anderies, B. Campbell, C. Folke, S. HatfieldDodds, T. P. Hughes, and J. Wilson. 2006. Governance and the capacity to manage resilience in regional social-ecological systems. Ecology and Society 11(1): 19. [online] URL: http:// www.ecologyandsociety.org/vol11/iss1/art19/

Li, T. M. 2002. Engaging simplifications: community-based resource management, market processes and state agendas in upland southeast Asia. World Development 30(2):265-283. http://dx.doi.org/10.1016/S0305-750X(01)00103-6

Li, W., and L. Huntsinger. 2011. China's grassland contract policy and its impacts on herder ability to benefit in Inner Mongolia: tragic feedbacks. Ecology and Society 16(2): 1. [online] URL: http://www.ecologyandsociety.org/vol16/iss2/ $\underline{\operatorname{art} 1 /}$

Li, Y. B., and W. J. Li. 2010. Feasibility of livestock breed improvement in agro-pastoral area of Inner Mongolia: a case 
study in Keshiketeng Banner, Chifeng. [NeiMeng Nongmu Jiaocuodai Jiachu Pinzhong Gailiang Kexingxing Fenxi-Yi Keshen Keteng Qi WeiLi]. Journal of Arid Land Resources and Environment [GanHanQu ZiYuan Yu HuanJing] 24 (6):189-195.

Liu, J., T. Dietz, S. R. Carpenter, M. Alberti, C. Folke, E. Moran, A. N. Pell, P. Deadman, T. Kratz, J. Lubchenco, E. Ostrom, Z. Ouyang, W. Provencher, C. L. Redman, S. H. Schneider, and W. W. Taylor. 2007. Complexity of coupled human and natural systems. Science 317(5844):1513-1516. http://dx.doi.org/10.1126/science.1144004

Livestock Breed Improvement Service of Inner Mongolia Autonomous Region (LBISOIMAR [NeiMengGu ZiZhiQu JiaChu GaiLiang GongZuo Zhan]), editor. 1983. Reports on livestock and poultry breed resources in Inner Mongolia Autonomous Region. [NeiMengGu ZiZhiQu JiaChu JiaQin PinZhong ZiYuan DiaoCha BaoGao HuiBian]. Hohhot, Inner Mongolia, China

Moll, H. A. J., S. J. Staal, and M. N. M. Ibrahim. 2007. Smallholder dairy production and markets: a comparison of production systems in Zambia, Kenya and Sri Lanka. Agricultural Systems 94(2):593-603. http://dx.doi.org/10.1016/ j.agsy.2007.02.005

Olsson, P., L. H. Gunderson, S. R. Carpenter, P. Ryan, L. Lebel, C. Folke, and C. S. Holling. 2006. Shooting the rapids: navigating transitions to adaptive governance of socialecological systems. Ecology and Society 11(1): 18. [online] URL: http://www.ecologyandsociety.org/vol11/iss1/art18/

Ostrom, E. 1990. Governing the commons: the evolution of institutions for collective action. Cambridge University Press, Cambridge, UK.

Ostrom, E. 2007. A diagnostic approach for going beyond panaceas. Proceedings of the National Academy of Sciences of the United States of America 104(39):15181-15187. http:// dx.doi.org/10.1073/pnas.0702288104

Ostrom, E. 2009. A general framework for analyzing sustainability of social-ecological systems. Science 325 (5939):419-422. http://dx.doi.org/10.1126/science.1172133

Party Committee of Inner Mongolia [Neimenggu Zizhiqu Dangwei]. 1961. Regulations on work for pastoral people's communes of Inner Mongolia Autonomous Region (Revised Draft). [NeiMengGu ZiZhiQu RenMin GongShe GongZuo TiaoLi (XiuZheng CaoAn)]. Pages 44-74 in Q. F. Su, editor. 1986. Selections of documents on animal husbandry in Inner Mongolia. [Neimenggu Xumuye Wenxian Ziliao Xuanbian]. Volume II (second half). Policy Study Division of Communist Party Committee of Inner Mongolian Autonomous Region [NeiMengGu DangWei ZhengCe YanJiu Shi]. Hohhot, Inner Mongolia, China.
Qi, B. Y. 2002. Animal husbandry chronicles of Xilingol League. [Xilin Gole Meng XuMuZhi]. People's Press of Inner Mongolia [NeiMengGu RenMin ChuBanShe], Hohhot, Inner Mongolia, China.

Rammel, C., S. Stagl, and H. Wilfing. 2007. Managing complex adaptive systems: a co-evolutionary perspective on natural resource management. Ecological Economics 63:9-21. http://dx.doi.org/10.1016/j.ecolecon.2006.12.014

Ratner, B. D. 2006. Community management by decree? Lessons from Cambodia's fisheries reform. Society \& Natural Resources 19(1):79-86. http://dx.doi.org/10.1080/089419205 $\underline{00323344}$

Robinson, L. W. 2009. A complex-systems approach to pastoral commons. Human Ecology 37(4):441-451. http://dx. doi.org/10.1007/s10745-009-9253-2

Sambu. 1981. Investigation report on Sonid Sheep [SuNiTe Yang DiaoCha BaoGao]. Pages 117-129 in Livestock Breed Improvement Service of Inner Mongolia Autonomous Region (LBISOIMAR [NeiMengGu ZiZhiQu JiaChu GaiLiang GongZuo Zhan]), editor 1983. Reports on livestock and poultry breed resources in Inner Mongolia Autonomous Region. Hohhot, Inner Mongolia, China.

Sanginga, P. C., R. N. Kamugisha, and A. M. Martin. 2007. The dynamics of social capital and conflict management in multiple resource regimes: a case of the southwestern highlands of Uganda. Ecology and Society 12(1): 6. [online] URL: http://www.ecologyandsociety.org/vol12/iss1/art6/

Scoones, I. C. 1990. Livestock populations and the household economy: a case study from southern Zimbabwe. Dissertation. Imperial College of Science and Technology, London, UK.

Scoones, I. 1999. New ecology and the social sciences: what prospects for a fruitful engagement? Annual Review of Anthropology 28:479-507. http://dx.doi.org/10.1146/annurev. anthro.28.1.479

Sick, D. 2008. Social contexts and consequences of institutional change in common-pool resource management. Society \& Natural Resources 21(2):94-105. http://dx.doi.org/ $\underline{10.1080 / 08941920701681524}$

Thorp, S. 2001. Looking to the past for the future. Appropriate Technology 28(1):47-48.

Tisdell, C. 2003. Socioeconomic causes of loss of animal genetic diversity: analysis and assessment. Ecological Economics 45(3):365-376. http://dx.doi.org/doi:10.1016/S09 21-8009(03)00091-0

Travis, J. 1992. Third world: s(ave) o(ur) s(heep)! Science, New Series 255(5045):678.

Walker, B., L. H. Gunderson, A. P. Kinzig, C. Folke, S. R. Carpenter, and L. Schultz. 2006. A handful of heuristics and 
some propositions for understanding resilience in socialecological systems. Ecology and Society 11(1): 13. [online] URL: http://www.ecologyandsociety.org/vol11/iss1/art13/

Wang, J. G. 2006. Agricultural-pastoral ecology and traditional Mongolian society. [NongMu ShengTai Yu ChuanTong MengGu SheHui]. Shandong People's Press [ShanDong RenMin ChuBanShe], Jinan, Shandong Province, China.

Wilson, C., and C. Tisdell. 2005. Globalisation, concentration of genetic material and their implications for sustainable development. School of Economics and Finance Discussion Papers and Working Papers Series No. 198, Queensland University of Technology, Brisbane, Australia. [online] URL: http://ideas.repec.org/p/qut/dpaper/198.html

Xie, Y., and W. Li. 2008. Why do herders insist on Otor? Maintaining mobility in Inner Mongolia. Nomadic Peoples 12 (2):35-52. http://dx.doi.org/10.3167/np.2008.120203

Xun, L. L. 2009. Disordered nature: ecology, power and morality in a grassland community. ['ShiXu' De ZiRan-YiGe CaoYuan SheQu De ShengTai, QuanLi Yu DaoDe]. Dissertation. Minzu University of China, Beijing, China.

Yeh, E. T. 2009. Greening western China: a critical view. Geoforum 40(5):884-894. http://dx.doi.org/10.1016/j.geoforu $\underline{\mathrm{m} .2009 .06 .004}$

Yu, Z. Y. 2003. First study of Inner Mongolia western region's natural disasters and disaster-policy in Qing Dynasty. [QingDaiNeiMengGu XiBu DiQu ZiRan ZaiHai Yu HuangZheng ChuTan]. Thesis. Inner Mongolia Normal University, Hohhot, Inner Mongolia, China.

Zhang, Q., and W. J. Li. 2008. Distributed overgrazing: a neglected cause of grassland degradation in Inner Mongolia. [FenBuXing GuoMu: YiGe Bei HuShi De NeiMengGu CaoYuan TuiHua De YuanYin]. Journal of Arid Land Resources and Environment [GanHanQu ZiYuan Yu HuanJing] 22(12):8-16. 